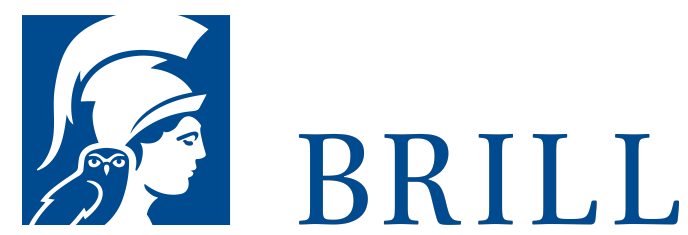

\title{
Die philonische Unterscheidung
}

AufklÃørung, Orientalismus und Konstruktion der Philosophie

Author: Dirk Westerkamp

Seit der frã̃/4hen Aufklãarung sind der Philosophie ihre auÃ ŸereuropÃøischen Traditionen zum Faszinosum geworden $\hat{a} €$ “ aber auch zu einem historiographischen Problem. Denn sie mussten aus der FÃ $1 / 4$ lle der Ã $1 / 4$ berlieferten Kenntnisse und Dokumente erst konstruiert werden. In diese Zeit fÃallt die Erfindung der Unterscheidungen von 'orientalischer', 'jÃ¹/4discher' und 'abendlÃandischer' Philosophie. 'Orientalismus' ist daher kein Streitbegriff postkolonialer Kulturwissenschaften, sondern stammt bereits aus den Kontroversen der AufklÃarung, deren Philosophiegeschichtsschreibung das j $\tilde{A}^{1 / 4}$ dische Denken als Schnittflãøche orientalischer und europãaischer Denkweisen begreift. Dabei rÃ $1 / 4 c k t$ zunehmend eine Unterscheidung in den Blick, die auf den j $\tilde{A}^{1 / 4}$ dischen Platoniker Philo von Alexandrien zurÃ $1 / 4$ ckgef $\tilde{A} 1 / 4$ hrt wird: die Differenz zwischen Gott und Logos, zwischen Substanz und Subjekt, zwischen Prinzip und Person im Absoluten selbst.

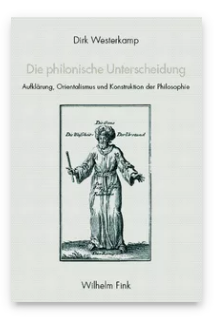

Pages: 237

Seiten

Language:

German

Subjects:

General,

Philosophy

Publisher: Brill |

Fink

E-Book (PDF)

Released online:

o9 Mar $202 \mathrm{O}$

ISBN: $978-3^{-}$

8467-4189-4

List price

US.D Â \$30.0o

Paperback

Publication date: 16 Sep 2009

ISBN: $978-3-$

7705-4189-8

List price

USD. Â $\$ 30.00$ 
For more information see brill.com

Order information: Order online at brill.com +44330 333 0049 | customerservices@brill.com Submission information: brill.com/authors

Titles published by Brill | Fink, Brill | mentis or Brill | Schöningh: +49(o)715413279216| brill@brocom.de 